\title{
CONSIDERATIONS REGARDINGTHE INTEGRATION-INTRICATION PROCESSIN THE NATURE AND TECHNOLOGY
}

\author{
CAMELIA VELIA TECARU (BEREKMERI) \\ Faculty of Machine Building, Technical University of Cluj-Napoca, Romania, berekmeri.camelia@gmail.com \\ IOAN BLEBEA \\ Faculty of Machine Building, Technical University of Cluj-Napoca, Romania, ioan_blebea@yahoo.com \\ CIPRIAN-RADU RAD \\ Faculty of Mechanical Engineering, Technical University of Cluj-Napoca, Romania,ciprian.rad@mdm.utcluj.ro
}

\begin{abstract}
The big challenges in education and $R \& D$ activities in the century just started are related on the complexity and transdisciplinarity understanding and promotion.The approaches are necessary in order to understand the unity of the world we live in through the unity of knowledge.The complexity is the result of the integration process.The paper presents fundamentals of the integration-intrication process in the nature and technology.The concept of integronics and the basic principles of the integration process are outlined too. Also the main features of mechatronics as environment for transdisciplinarity learning and the concept of integral education promotion are presented.The advanced mechatronics and the embedded systems are fundamentals of the cyberphysical systems of the future.
\end{abstract}

Keywords: mechatronics, integration, knowledge, intrication, transdisciplinarity

\section{Introduction}

The evolution and development of the human society is closely related to the technology evolution. This connection is easily understandable if we take into account the fact that starting from the Stone Age technology we are now in the information technology age. The transitions in that evolution were marked by revolutions. Thus, the following revolutions are mentioned: material revolution, energy revolution, quantum revolution, information technology revolution and mechatronic revolution (Mătieş, 2009). Information technology revolution marked up the shift from industrialized society to information society, generating a new wave of innovations in technology and education. These innovations were defined by the Japanese at the beginning of the $8^{\text {th }}$ decade of the last century when the word mechatronics was patented(Kajitani,1992).

Decisions taken at government level in the ninth decade of the last century, projects and programs developed at national level in the U.S., EU countries and beyond, to promote mechatronic philosophy in education and R\&D activites, had the character of a true revolution, the mechatronic revolution (Peters, 1989;Mătieş, 2009). This marked up the transition from information-based society to knowledge-based society.

On the other hand, in the last two decades, an intense shift from advanced mechatronic systems to cyber physical systems (CPS) is taking place(Horvath, 2012; Marwedel,2011).Cyber-physical systems are engineering systems that are built from upon the synergy of computational and physical components. The CPS of tomorrow will need to far exceed the systems of today in capability, adaptability, resiliency, safety, security, and usability. Examples of the many CPS application areas include the smart electric grid, smart transportation, smart buildings, smart medical technologies, next generation air traffic management, advanced manufacturing etc. CPS will transform the way people interact with engineering systems, just as the internet transformed the way people interact with information. However, these goals cannot be achieved without rigorous systems engineering.Advanced mechatronics and embedded systems are the foundation of CPS development (Horvath, 2012; Marwedel,2011). To expedite and accelerate the realization of cyberphysical systems in a wide range of applications, it is necessary to develop methods, tools, and hardware 
and software components based upon cross-cutting principles, along with validation of the principles via prototypes and test beds.

These changes in technological, economical, social and cultural fields launched new challenges for schools and universities regarding the development of new educational technologies to meet the new requirements for education and training specialists in accordance with the requirements of the knowledge society.Learning transdisciplinarity and promoting the concept of integral education are the main challengis to strengthen the pillars of education in the knowledge society.The transdisciplinarityis defined as: "what is in the same time, in between disciplines, inside different disciplines, and beyond any discipline"the finality of the transdisciplinary measure is the understanding of the world through the unity of knowledge (Nicolescu, 1999; Nicolescu, 2002). The concept of integral education developed in the papers(Nicolescu, 1999; Nicolescu,2002),brings into attention educational and technological approaches where the subject participate in the educational process with his whole being (mind, emotions and physical).

That is possible bylearning and understanding the integration-intrication process inthe nature and technology and the role of information and information links in that processes (Nicolescu, 1999; Nicolescu,2002; Mătieş 2009). The paper presents details related on that field.

\section{Fundamentals of the integration process}

Integration is a natural process. In the literature are developed concepts like: integration philosophy, logic of integration (Szabo, 2006).In the paper (Jacob, 2002), the author defined the concept of integron as a messenger of integration, showing that the human body is the result of integrons hierarchy. The integration is the mechatronic paradigm(Kajitani, 1992; Peters, 1989; Mătieş 2009) and knowledge is the result of structuring and integrating information. Integronics as the science of integration processes and hyperintegrated systems(Szabo, 2006; Mătieş, 2009)deals with integration levels, integration degrees, hyperintegrated systems and the benefits of integration process. The concept is presented in the Figure 1.

Integronics developed starting from the limits of the theory of systems and of cybernetics; they are very close to the integral outlook of the world, still they have never succeeded in explaining the way in which systems arise and develop and especially the way in which they depend on one another and influence one another. Since it deals precisely with the manner in which various aspects and phenomena interpenetrate, integronics can contribute to optimize the solutions. Besides its theoretic importance, integronics may have a special practical importance too since it help us to know the unity of the world we live in.

Integration is not a useless process. On the contrary, integration gives new possibilities to control the systems. Integration gives the possibility of association to complementary elements, the possibility of connecting, of forming cycles and networks. But integration also gives the possibility of obtaining a surplus of elements, a structural redundancy. In the case of hyperintegrated systems (e.g. human body) where everything is linked to everything and everything depends on everything, the structural redundancy results in a fantastic combinatory redundancy. Integration therefore gives the systems larger possibilities to maintain their identity despite the second principle of thermodynamics.

Figure 1: The concept of integronics

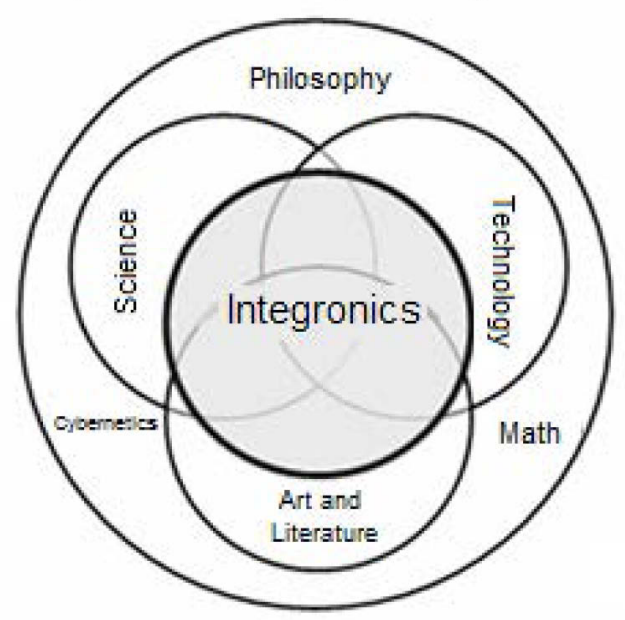

In the integration process a special role is attached to information, and informational links since elements have to recognize one another in order to be able to unite in increasingly organized systems. For this 
reason, each element transports the substance and energy it consists of, structural information that can be recognized by the other elements. In this way, some elements attract and other rejects one another, giving birth to extremely varied systems (Szabo, 2006; Mătieş,2009). The basic principles of the integration process are: the principle of superization, the principle of order and organization and principle of integration, intricateness and diversification of systems.If systems are integrated in larger and larger systems, these systems become more and more complex and therefore more and more diversified and differentiated. The elements or subsystems can be genetically integrated or by force integrated. An elementary particle can be captured by the atomic nucleus that will sbsequently keep it by force, a force that will not allow it to leave the respective nucleus.In the structure of a gear box the elements are also integrated by force. Besides genetic integration and integration by force, elements can also be integrated by being made dependent on the respective system. Such is, for instance, the case of ecological systems; plants and animals depend so much on one another that they cannot even live outside the respective system. Elements can often choose the system to which they will belong as happens in social systems. That is why we can speak of integration at choice.Finally integration is sometimes accidental. If elementary particles collide by chance, thus is engendering other elementary particles, the hazard also plays a certain part in the integration processes. In the case of more complex systems there also appear integration subsystems, such as the nervous system, the endocrine system and the cardiovascular system that have the role of coordinating the millions of cells of the body (Szabo, 2006; Mătieş, 2009).In the field of mechatronic systems the approaches to get integration of the elements of the threemain fields of engineering are based on hardware integration and software integration.

\section{The concept of mechatronics}

The word mechatronics, patented by the Japanese at the beginning of the eighth decade of the last century, was used to describe the integration of the three major areas of engineering: mechanical engineering electrical engineering, electronics - control science and, computer science (Peters, 1989; Kajitani, 1992; Mătieş, 2009). The main feature of the mechatronic systems is dualism: energy flow - information flow. Information links and information kinematic chains ensure flexibility and reconfigurability of the mechatronic systems. Mechatronics was born as a technology and very soon became philosophy, science of intelligent machines and now, in the knowledge based society it is environment for transdisciplinarity learning and the concept of integral education promotion. For engineering practice, mechatronics has marked the shift from traditional, sequential engineering to concurrent (parallel) engineering. So that the concepts of integrated design or design for control were developed (Bradley, 2010; Mătieş, 2009). In that context, the problems related on the integrationinterfacing process, the information links and the control function integration are to be taken into account very early, in the stage of the conceptual design. The flow to mechatronic integration is suggestively highlighted in Figure 2 (Peters, 1989; Kajitani, 1992; Mătieş, 2009).

Figure 2:Technological flow to mechatronic integration

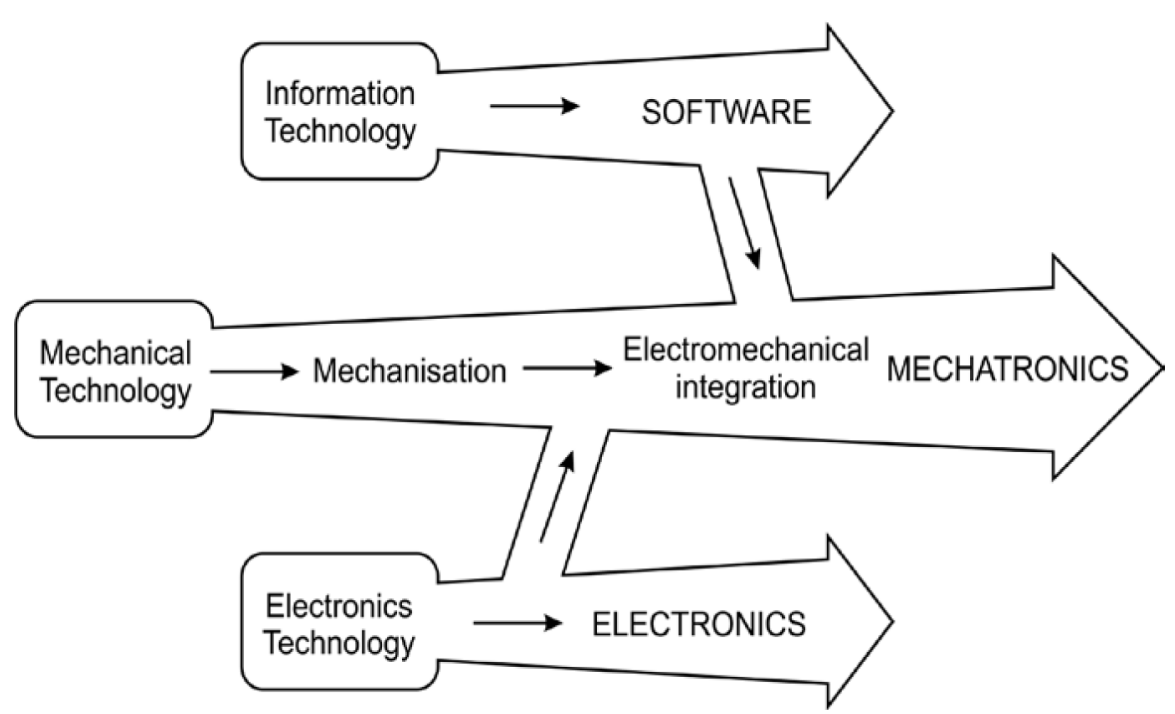

Traditionally, mechanical technology dealt mainly with the problems of energy and material. The progress of semiconductors, especially integrated circuits, made it possible the integration of machines and electronics in one body. However, at this stage, the system could not have intelligence yet. Next revolution began with the appearance of microcontrollers. Small and cheap microprocessors have been integrated into machines, and permitted machines to think and take decisions. Than, mechanical technology has changed 
to mechatronics by merging information-processing functions.

Mechatronics represents an integrative vision in technological field, as shown graphically in Figure 3. The importance of mechatronics is evidenced by the myriad of smart products that we take for granted in our daily lives, from the cruise control feature in our cars to advanced flight control systems and from washing machines to multifunctional precision machines.

The basic components of the mechatronic technology are: material, energy and information.The information is the most important element, by comparing against material and energy. The reasons why are: satisfaction of the mind of human beings is caused by information; only information can increase added value of all things (Kajitani, 1992).

Figure 3: The concept of mechatronics

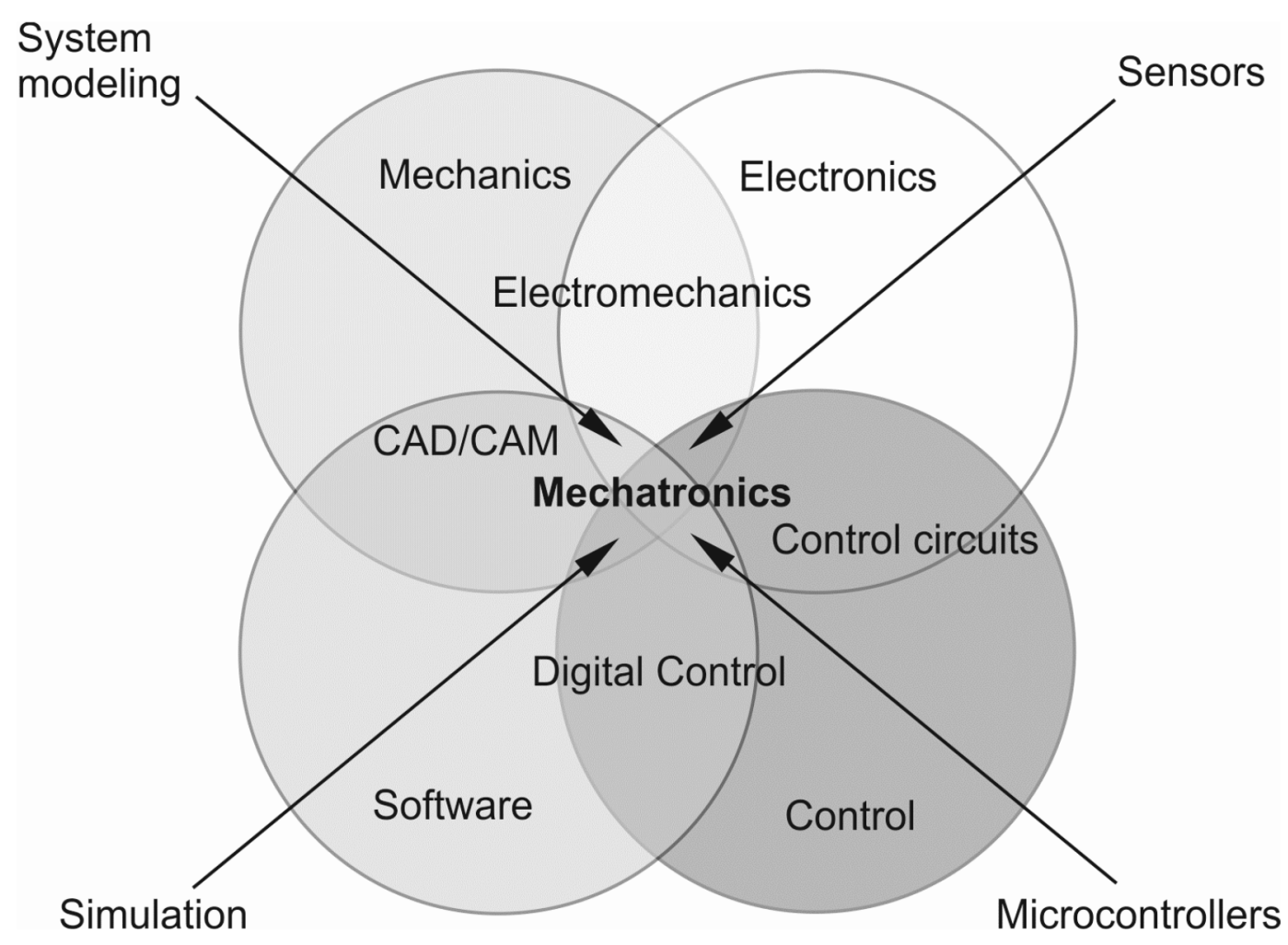

\subsection{Mechatronics and complexity}

Through a mechanism of stimulating transdisciplinary ideas and techniques, mechatronics provides ideal conditions to raise the synergy, thereby providing a catalytic effect for the new solutions to technically complex situations. The mechatronic approaches are very knowledge intensive (Figure 4). They combine kinematics and dynamics, material technology, control engineering, information technology, micro technology etc.

Mechatronic knowledge is a technological one, or knowledge about how to manufacture intelligent products, systems and services (Mătieş, 2009). Taking into account the trans-thematic identity of mechatronics based on the complexity concept, mechatronic knowledge is transdisciplinary one (Berian, 2010; Nicolescu,1999; Nicolescu, 2002). Learning transdisciplinarity is a major need in the knowledge based society. Mechatronic platforms are the basic infrastructure of the environment for transdisciplinarity learning and the concept of integral education promotion. 
Figure 4: The complexity concept as basis for trans-thematic identity of mechatronics

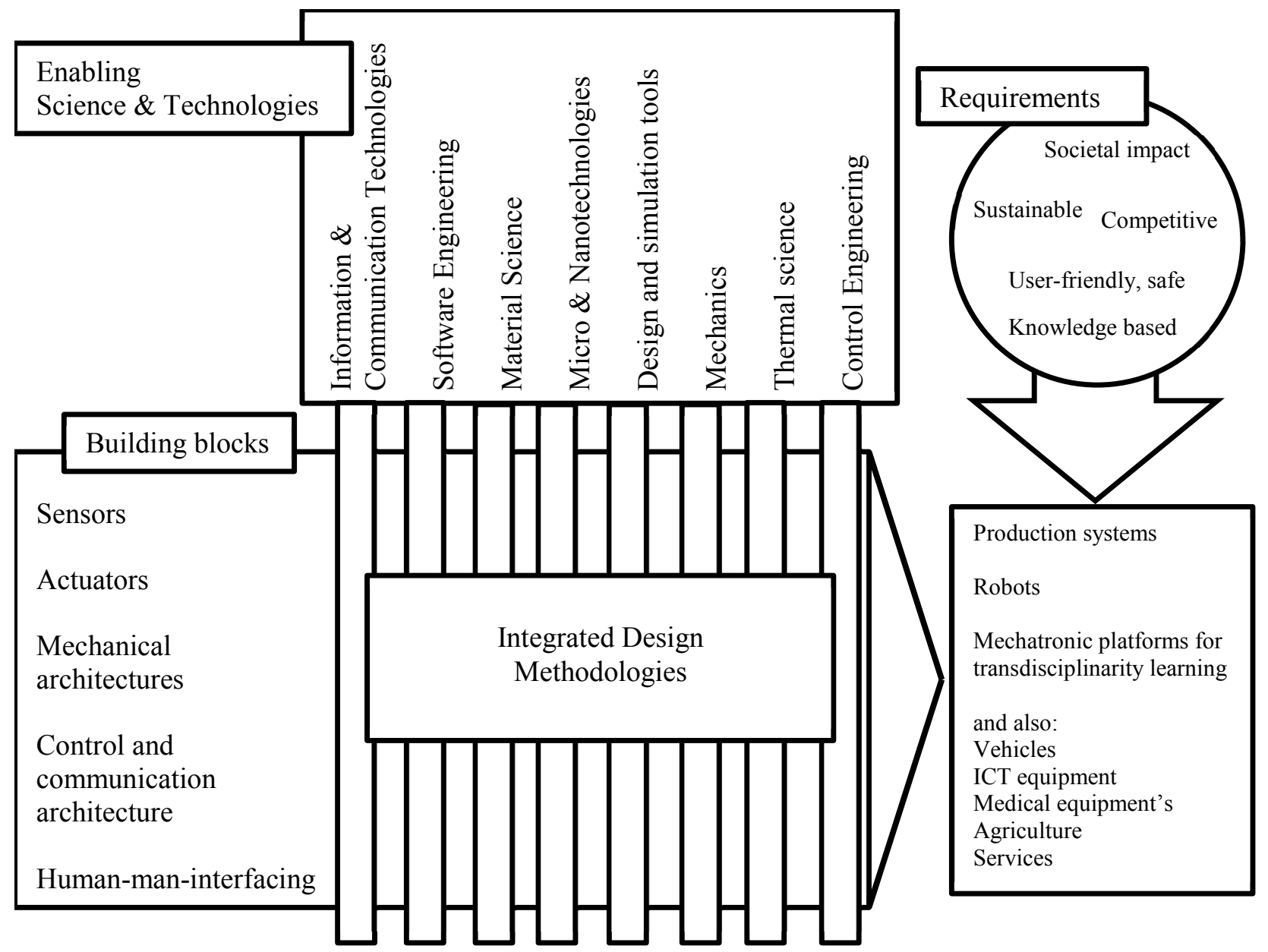

\section{Conclusions}

As it is emphasized in the literature, the $21^{\text {st }}$ century will belong to complexity. The complexity is closely related to the idea of non-separability, which "seems to be a fundamental principle of all that is profound in the world"(Berian,2010; Nicolescu 1999; Nicolescu, 2002). Consequently, research and education of the future must be shaped by the force lines of the complexity and non-separability.The complexity is the result of the integration process. The paper presents usefull details to understand the integration process in the nature and technology.On the other hand, mechatronics as a technology of the $21^{\text {st }}$ century ensures the necessary tools in education and R\&D activities to develop the cyber-phisical systems of the future.

Acknowledgment: This paper was supported by the project "Improvement of the doctoral studies quality in engineering science for development of the knowledge based society - QDOC" contract no. POSDRU/107/1.5/S/78534, project co-founded by the European Social Found through the Sectorial Operational Programe Human Resources 2007-2013.

\section{References}

- Berian, S. (2010), Researches regarding the transdisciplinary potential of mechatronics, $\mathrm{PhD}$ Thesis, Technical University of Cluj-Napoca (in Romanian language).

- Berian, S., Maties, V. (2011), Transdisciplinarity and Mechatronics, Curtea Veche Publishing, Bucharest, Romania, ISBN 978-606-588-199-0 (in Romanian language).

- Bradley,D.,Russell,D.W.(Ed),(2010),Mechatronics in Action. Case Studies in MechatronicsApplications and Education,Springer-Verlag London Limited,ISBN 978-1-84996-079-3.

- Carryer,J.E.et al.,(2011),Introduction to Mechatronic Design, Pearson,Ney Jersey, ISBN -13-978-0-13609521-7.

- Draganescu, M. (2001), Informational and Knowledge based Society. Vectors of knowledge based society, http://www.edemocratie.ro/pub_vectorii_soccun.html (in Romanian language). 
- Horvath, I., (2012), Beyond advanced mechatronics: new design challenges of social-cyber-physical systems, Proceedings of the ACCM-Workshop on "Mechatronic Design", November 30, Linz, Austria.

- Jacob, F. (2002), Die Logik des Lebenden: Eine Geschichte der Vererbung, Fischer Verlag, Frankfurt, October, Deutsch, ISBN: 3-596-14468-X.

- Kajitani, M. (1992), What has brought Mechatronics into existence in Japan?, Proceeding of the 1st France-Japan Congress of Mechatronics, Besancon, France.

- Marwedel, P., (2011), Embeded Systems Foundations of Cyber-Physical Systems, Springer Dordrecht Heidelberg, London, ISBN 978-94-007-0256-1.

- Mătieş, V., et al. (2009), Mechatronic platforms for education and research, Todesco Publishing, ClujNapoca, Romania, ISBN 978-973-7695-79-6 (in Romanian language).

- Nicolescu, B. (1999), Transdisciplinarity. Manifest, Polirom Publishing, Iasi, Romania, ISBN 973-683234-1 (in Romanian language).

- Nicolescu, B. (2002), We, the particle and the world, Rocher, Paris.

- Peters, J., Van Brussel, H. (1989), Mechatronic Revolution and Engineering Education, European Journal of Mechanical Engineering, Vol. 34, Nr. 1, Pag. 5-8.

- Szabo, F. (2006), Contributions regarding the study of integration process in Mechatronics, $\mathrm{PhD}$ Thesis, Technical University of Cluj-Napoca (in Romanian language). 